\title{
Comportamento ingestivo de cordeiros alimentados com dietas contendo diferentes níveis de fibra em detergente neutro
}

\author{
Ingestive behavior of lambs fed with a diet of different levels of fiber in neutrol detergent
}

\author{
Adriano Ramos Cardoso ${ }^{1}$ Sérgio Carvalho ${ }^{2}$ Diego Barcelos Galvani ${ }^{3}$ Cléber Cassol Pires ${ }^{5}$ Bernardo \\ Garziera Gasperin $^{5}$ Renata Porto Alegre Garcia ${ }^{6}$
}

\section{RESUMO}

\begin{abstract}
Avaliou-se o efeito de diferentes níveis de fibra em detergente neutro (FDN), na dieta sobre o comportamento ingestivo de cordeiros Ile de France $x$ Texel. Foram utilizados 20 cordeiros distribuídos em um delineamento experimental inteiramente casualizado, em um total de quatro tratamentos com cinco repetições, e alimentados à vontade com dietas que continham 25\%, 31\%, 37\% e 43\% de FDN. Foi utilizada uma ração em mistura completa de silagem de sorgo (AG 2005E) e mistura concentrada constituída por farelo de soja, grão de milho quebrado e mistura mineral. As dietas eram isoprotéicas contendo $17 \%$ de PB. As dietas foram fornecidas duas vezes ao dia, às 8:00 e às 16:00 horas. O comportamento ingestivo foi determinado mediante observação visual, ocorrido durante 24 horas, a intervalos de 5 minutos, para se determinar o tempo despendido em alimentação, ruminação e ócio. $O$ aumento do teor de fibra na ração não influenciou significativamente $(P>0,05)$ os tempos despendidos em alimentação, ruminação, ócio e tempo de mastigação total. Houve efeito linear crescente sobre as variáveis eficiência de alimentação e de ruminação de FDN $(P>0,05)$. Os ovinos confinados possuem hábito de alimentação predominantemente diurno e de ruminação noturno.
\end{abstract}

Palavras-chave: ingestão, ócio, ovinos, ruminação.

\section{ABSTRACT}

The effect of different neutral detergent fiber (NDF) levels in the diet on the Ile de France $x$ Texel lambs ingestive behavior was evaluated. Twenty lambs distributed in a fully randomized experimental design were used, in a total of four treatments and five repetitions, fed ad libitum with $25 \%$, 31\%,

\begin{abstract}
$37 \%$ and $43 \%$ NDF diets. A ration in a complete mixing in sorghum silage (AG 2005 E) and concentrate mixing of soybean meal, fragmented corn grains and mineral mixing was used. The diets were isoproteic (17\% crude protein) and were given twice a day, at $8 \mathrm{AM}$ and $4 \mathrm{PM}$. The ingestive behavior was determined by observation, during 24 hours with 5 minutes intervals, to determine the time spent in feeding, rumination and idleness. The increase of the fiber level in the feed did not effect $(P>0.05)$ on the time spent in feeding, rumination, idleness and total chewing time. The rumination and feeding efficiency increased linearly $(P<0.05)$, as the dietary NDF levels increased. The feedlot sheeps have predominantly diurnal habit of feeding and nocturnal of rumination
\end{abstract}

Key words: feeding, idleness, sheep, rumination.

\section{INTRODUÇÃO}

Os sistemas modernos de criação de ovinos, com adoção de práticas de manejo e alimentação adequadas, possibilitam melhor desempenho dos animais e, por conseqüência, melhor retorno econômico. A terminação de cordeiros em confinamento é uma alternativa capaz de proporcionar o abate precoce dos animais, resultando em carcaças com características desejáveis que atendam às exigências de mercado, garantindo ao produtor o retorno mais rápido do capital investido (OLIVEIRA et al., 2002). No entanto, as maiores desvantagens do uso deste sistema

${ }^{1}$ Pós-graduação em Zootecnia, Universidade Federal de Santa Maria (UFSM), Santa Maria, RS, Brasil. E-mail: zootarc@terra.com.br ${ }^{2}$ Centro Universitário Feevale, Novo Hamburgo, RS, Brasil. E-mail: sergiocarvalho@feevale.br.

${ }^{3}$ Curso de Zootecnia, UFSM, Santa Maria, RS, Brasil.

${ }^{4}$ Depto Zootecnia, UFSM, Campus Camobi, 97105-900, Santa Maria, RS, Brasil. E-mail: cpires@ccr.ufsm.br

${ }^{5}$ Curso de Medicina Veterinária, UFSM, Santa Maria, RS, Brasil.

${ }^{6}$ Curso de Zootecnia, UFSM, Santa Maria, RS, Brasil. 
se encontram nos altos custos de produção, principalmente em alimentação, que constitui um fator determinante no aspecto financeiro.

Segundo MERTENS (1987), o consumo de matéria seca é a variável mais importante que influencia o desempenho animal, sendo inversamente relacionada ao conteúdo de fibra da dieta. Dietas com elevada concentração de fibra limitam a capacidade ingestiva do animal, em virtude da repleção do retículo-rúmen. Por outro lado, dietas com teores reduzidos de fibra também resultam em menor ingestão total de MS, uma vez que as exigências energéticas do animal podem ser atingidas em níveis mais baixos de ingestão, podendo, ainda, ocasionar distúrbios digestivos que comprometem a saúde animal, levando à redução do desempenho produtivo.

O conhecimento do comportamento ingestivo é uma ferramenta de grande importância na avaliação das dietas, pois possibilita ajustar o manejo alimentar dos animais para obtenção de melhor desempenho produtivo. De acordo com HODGSON (1990), os ruminantes adaptam-se às diversas condições de alimentação, manejo e ambiente, modificando seus parâmetros de comportamento ingestivo para alcançar e manter determinado nível de consumo, compatível com as exigências nutricionais. Animais confinados gastam em torno de uma hora consumindo alimentos ricos em energia, ou até mais de seis horas, para fontes com baixo teor de energia e alto em fibra. Da mesma forma, o tempo despendido em ruminação é influenciado pela natureza da dieta e, provavelmente, é proporcional ao teor de parede celular dos volumosos. Assim, quanto maior a participação de alimentos volumosos na dieta, maior será o tempo despendido com ruminação (VAN SOEST, 1994).

Segundo WELCH \& HOOPER (1988), o tempo de ruminação é altamente correlacionado $(0,96)$ com o consumo de FDN em bovinos. ALBRIGHT (1993), em experimento com vacas, relatou para três níveis de FDN na dieta (26, 30 e 34\%), valores para os tempos despendidos em ruminação e total de mastigação de 344 e 558; 403 e 651; 414 e 674min dia-1 , respectivamente.

São escassos na literatura dados referentes aos níveis de FDN na dieta de ovinos que possibilitem compreender melhor os aspectos produtivos. Assim, o objetivo deste trabalho foi avaliar o comportamento ingestivo de cordeiros alimentados com dietas contendo diferentes níveis de fibra em detergente neutro, para que haja melhor entendimento dos processos que controlam a ingestão de alimento e, conseqüentemente, o desempenho animal.

\section{MATERIAL E MÉTODOS}

O experimento foi conduzido no Setor de Ovinocultura, do Departamento de Zootecnia da Universidade Federal de Santa Maria (UFSM), localizada fisiograficamente na Depressão Central do Estado do Rio Grande do Sul, no período compreendido entre agosto e dezembro de 2003. Conforme a classificação de Köppen, o clima da região é o Cfa (subtropical úmido), com precipitação média anual de $1.769 \mathrm{~mm}$, temperatura média anual de $19,2^{\circ} \mathrm{C}$, média mínima de $9,3^{\circ} \mathrm{C}$ em julho e média máxima de $24,7^{\circ} \mathrm{C}$ em janeiro, insolação de 2.212 horas anuais com umidade relativa do ar de 82\% (MORENO, 1961).

Foram utilizados 20 cordeiros, machos não castrados, cruza Ile de France x Texel, desmamados em média aos 42 dias de idade com peso médio 19,28 kg. Os animais foram distribuídos aleatoriamente em quatro tratamentos: 25, 31, 37 e 43\% de FDN, sendo alojados em baias individuais, com área de $2 \mathrm{~m}^{2}$ providas de comedouros e bebedouros.

Antes do início do período experimental, os animais passaram por um período de adaptação (7 dias), em que receberam, ad libitum, uma dieta contendo 35\% de FDN e 17\% de PB. Após este período, passou-se a fornecer a dieta correspondente a cada tratamento. A alimentação foi fornecida duas vezes ao dia, em horários preestabelecidos às 8:00 e às 16:00 horas, ajustada de forma a manter as sobras em $10 \%$ do oferecido. $\mathrm{O}$ alimento utilizado foi composto por silagem de sorgo (Sorghum bicolor (L.) Moench), grão de milho quebrado (Zea mays L.), farelo de soja (Glycine Max L.) e mistura mineral. A proporção entre volumoso e concentrado variou de forma a atingir os níveis de FDN desejados. As rações utilizadas foram calculadas para serem isoprotéicas, com 17\% de PB (MS). A proporção dos ingredientes utilizados na formulação das rações e a composição bromatológica da silagem e dos concentrados utilizados nas dietas experimentais são apresentados na tabela 1 .

Durante o experimento, a fim de controlar a ingestão de alimento, efetuou-se a pesagem diária do alimento oferecido e das sobras. Coletaram-se diariamente amostras dos alimentos fornecidos e das respectivas sobras, as quais foram identificadas e acondicionadas em freezer, para posteriores análises laboratoriais. Todas as amostras foram pré-secadas em estufa ventilada a $65^{\circ} \mathrm{C}$ e, posteriormente, moídas em moinho tipo "Willey” com peneira de $1 \mathrm{~mm}$. A seguir, foram acondicionadas em frascos identificados, para posterior determinação de MS, MO, FDN, FDA, PB e EE, segundo SILVA(1990). Os carboidratos totais (CHT) dos alimentos fornecidos e das sobras foram calculados 
Tabela 1 - Proporções dos ingredientes (\% MS) utilizados na formulação das rações e teores médios de matéria seca (MS), matéria orgânica (MO), proteína bruta (PB), extrato etéreo (EE), fibra em detergente neutro (FDN), fibra em detergente ácido (FDA), carboidratos totais (CHT), carboidratos não estruturais (CNE), cinzas (CIN), energia digestível (ED), cálcio (Ca) e fósforo (P), da silagem e dos concentrados utilizados na composição das dietas experimentais.

\begin{tabular}{|c|c|c|c|c|c|}
\hline \multirow[b]{2}{*}{ Ingredientes } & \multicolumn{5}{|c|}{ Tratamentos } \\
\hline & $25 \%$ & \multicolumn{2}{|c|}{$31 \%$} & $37 \%$ & $43 \%$ \\
\hline Silagem de Sorgo & 33,09 & \multicolumn{2}{|c|}{47,31} & 61,55 & 75,78 \\
\hline Milho Quebrado & 45,15 & \multicolumn{2}{|c|}{30,30} & 15,43 & 0,58 \\
\hline Farelo de Soja & 20,03 & \multicolumn{2}{|c|}{20,78} & 21,54 & 22,33 \\
\hline Calcário Calcítico & 1,13 & \multicolumn{2}{|c|}{0,90} & 0,68 & 0,45 \\
\hline Fosfato Bicálcico & 0,00 & \multicolumn{2}{|c|}{0,11} & 0,20 & 0,30 \\
\hline \multirow[t]{2}{*}{ Sal comum } & 0,60 & \multicolumn{2}{|c|}{0,60} & 0,60 & 0,60 \\
\hline & \multicolumn{4}{|c|}{ Concentrados } & \\
\hline Teores & 25 & 31 & 37 & 43 & Silagem \\
\hline MS & 89,39 & 89,21 & 89,23 & 89,78 & 35,52 \\
\hline MO & 94,94 & 94,33 & 93,36 & 91,01 & 94,94 \\
\hline $\mathrm{PB}$ & 19,85 & 25,06 & 31,12 & 40,56 & 6,25 \\
\hline $\mathrm{EE}$ & 2,84 & 2,44 & 2,61 & 2,58 & 2,55 \\
\hline FDN & 11,6 & 10,9 & 11,3 & 14,9 & 53,7 \\
\hline FDA & 1,5 & 1,3 & 1,5 & 3,9 & 27,9 \\
\hline CHT & 72,08 & 66,73 & 59,42 & 47,75 & 85,82 \\
\hline CNE & 60,65 & 55,93 & 48,33 & 32,97 & 32,44 \\
\hline CIN & 5,06 & 5,67 & 6,64 & 8,9 & 5,06 \\
\hline ED (Mcal/kg) & 3,87 & 3,66 & 3,90 & 3,76 & 2,51 \\
\hline $\mathrm{Ca}$ & 0,68 & 0,76 & 0,90 & 1,18 & 0,34 \\
\hline $\mathrm{P}$ & 0,41 & 0,48 & 0,60 & 0,87 & 0,17 \\
\hline
\end{tabular}

segundo SNIFFEN et al. (1992), em que CHT (\%) $=100$ - (\%PB + \%EE + \%CIN), e os carboidratos nãoestruturais (CNE), pela diferença de CHT - FDN. O consumo diário de nutrientes foi calculado pela diferença entre as quantidades ofertadas e seus respectivos conteúdos nas sobras.

Os animais foram submetidos à observação visual para avaliação do comportamento ingestivo, sendo observados a cada cinco minutos, durante 24 horas subdivididas em oito períodos de três horas, para determinação do tempo despendido em ingestão, ruminação e ócio, conforme metodologia citada por JOHNSON \& COMBS (1991). Durante a observação noturna dos animais, o ambiente foi mantido com iluminação artificial.

Os resultados referentes aos fatores do comportamento ingestivo foram obtidos utilizando-se as seguintes equações: $\mathrm{EI}_{\mathrm{MS}}=\mathrm{CMS} / \mathrm{TI}, \mathrm{EI}_{\mathrm{FDN}}=\mathrm{CFDN} /$ TI em que $\mathrm{EI}_{\mathrm{MS}}$ (g MS ingerida/h) e $\mathrm{EI}_{\mathrm{FDN}}$ (g FDN ingerida/h) = eficiência de ingestão; CMS (g) = consumo diário de matéria seca; $\mathrm{CFDN}$ (g) = consumo diário de FDN; TI = tempo gasto em ingestão diariamente. ERU $_{\mathrm{MS}}$ $=\mathrm{CMS}_{\text {TRU, }} \mathrm{ERU}_{\mathrm{FDN}}=\mathrm{CFDN} / \mathrm{TRU}$ em que $\mathrm{ERU}_{\mathrm{MS}}{ }_{\mathrm{MS}} \mathrm{g}$ MS ruminada/h) e ERU ${ }_{F D N}$ (g FDN ruminada/h) = eficiência de ruminação; CMS (g) = consumo diário de matéria seca; CFDN (g) = consumo diário de FDN; TRU $(\mathrm{h} / \mathrm{dia})=$ tempo gasto em ruminação diariamente. TMT $=\mathrm{TI}+\mathrm{TRU}$ em que TMT $(\mathrm{min} / \mathrm{dia})=$ tempo de mastigação total.

O delineamento experimental utilizado foi o inteiramente casualizado com quatro tratamentos e cinco repetições, sendo cada cordeiro considerado uma unidade experimental. Os dados foram submetidos à análise de variância e regressão, com auxílio do pacote estatístico SAS (SAS, 1997).

\section{RESULTADOS E DISCUSSÃO}

Os resultados referentes aos tempos despendidos em ingestão, ruminação, ócio e mastigação total, em função do nível de FDN das dietas, encontramse na tabela 2. Não houve influência dos níveis de FDN $(\mathrm{P}>0,05)$ sobre o tempo despendido pelos animais em ingestão, ruminação e ócio, bem como sobre o tempo de mastigação total.

O comportamento de ingestão observado neste estudo não está de acordo com a literatura, pois segundo MERTENS (1996), o conteúdo de fibra é inversamente relacionado ao conteúdo de energia líquida e, ao se elevar o nível de FDN da dieta, ocorre 
Comportamento ingestivo de cordeiro alimentados com dietas contendo diferentes níveis de fibra...

Tabela 2 - Tempo médio despendido pelos animais em ingestão, ruminação, tempo de mastigação total (TMT), ócio e outras atividades, em minutos por dia, em função dos níveis de FDN das dietas experimentais.

\begin{tabular}{|c|c|c|c|c|c|c|c|}
\hline \multirow[b]{2}{*}{ Variáveis } & \multicolumn{4}{|c|}{ NÍVEL DE FDN } & \multirow[b]{2}{*}{$\mathrm{R}^{2}$} & \multirow[b]{2}{*}{ CV (\%) } & \multirow[b]{2}{*}{ ER } \\
\hline & 25 & 31 & 37 & 43 & & & \\
\hline Ingestão & 217,50 & 213,75 & 213,75 & 177,50 & ---- & 16,49 & $Y=205,62$ \\
\hline Ruminação & 450,00 & 472,50 & 508,75 & 501,25 & ---- & 15,51 & $Y=483,12$ \\
\hline TMT & 667,50 & 686,25 & 722,50 & 678,75 & ---- & 12,54 & $Y=688,75$ \\
\hline Ócio & 761,25 & 748,75 & 710,00 & 758,75 & ---- & 11,71 & $\mathrm{Y}=744,69$ \\
\hline Outros & 11,25 & 5,00 & 7,50 & 2,50 & ---- & 79,13 & $Y=6,56$ \\
\hline
\end{tabular}

um aumento no tempo gasto para ingestão, de modo que o animal possa suprir suas exigências energéticas. Esta afirmação é corroborada por CARVALHO (2002), que trabalhou com diferentes níveis de FDN na dieta de cabras em lactação e observou aumento linear $(\mathrm{P}<0,01)$ no tempo despendido em ingestão à medida que se elevou o nível da fibra das dietas.

Segundo VAN SOEST (1994), o tempo gasto em ruminação é proporcional ao teor de parede celular dos alimentos, assim, ao elevar-se o nível de FDN das dietas haverá um aumento no tempo despendido com ruminação. Da mesma forma, CHURCH (1988) cita que forragens com alto conteúdo de FDN necessitam de maior tempo para ruminação, devido à maior necessidade de processar a fibra da dieta.

MENDONÇA et al. (2004), analisando o comportamento ingestivo de vacas leiteiras estabuladas, alimentadas com silagem de milho ou cana-de-açúcar em diferentes relações volumoso: concentrado (50:50 e 60:40), não encontraram diferenças nos tempos despendidos com alimentação e ruminação, resultado este que é corroborado pelos encontrados no presente estudo. Por outro lado, GONÇALVES et al. (2001), trabalhando com cabras leiteiras, alimentadas com dietas com diferentes relações volumoso:concentrado (100:0; 80:20; 60:40; 40:60 e 20:80), verificaram que, com o aumento do nível de volumoso e conseqüentemente, de fibra nas dietas, houve aumento nos tempos despendidos com ingestão e ruminação e, em contrapartida, houve diminuição no tempo despendido com ócio. DULPHY et al. (1980) relataram que aumentando a proporção de concentrado nas dietas e diminuindo o teor de fibra, o tempo despendido em ruminação decresce. Este fato foi confirmado por BÜRGER et al. (2000), os quais trabalhando com bezerros holandeses, verificaram que os tempos médios gastos com ingestão e ruminação diminuíram linearmente com o aumento do nível de concentrado nas dietas, ao contrário do que ocorreu com o tempo de ócio, que aumentou linearmente. No entanto, estes autores utilizaram dietas nas quais os níveis de FDN eram bastante superiores aos utilizados no presente estudo. Assim, a discordância entre resultados dos autores citados, possivelmente, possam estar relacionadas aos níveis de FDN das dietas experimentais, bem como à amplitude de variação destes (menor e maior nível), uma vez que, nos trabalhos de BÜRGER et al. (2000) e GONÇALVES et al. (2001), o nível de FDN e a amplitude de variação deste entre as dietas testadas foram superiores a 60 e $40 \%$, respectivamente, enquanto MENDONÇA et al. (2004) trabalharam com nível máximo de 37\% e amplitude de apenas $7 \%$.

Os valores médios observados para os tempos de alimentação (205,25 min/dia) e de ruminação $\left(487,25 \mathrm{~min} \mathrm{dia}^{-1}\right)$ são superiores aos encontrados por TURINO (2003) que obteve médias de 154,8 e 215,4min dia $^{-1}$ para alimentação e ruminação, respectivamente. No entanto, este autor trabalhou com dietas que continham alta proporção de concentrado de forma a compor dietas com um máximo de 18\% de FDN na MS.

Os resultados referentes às médias do consumo de matéria seca, consumo de fibra em detergente neutro, eficiência de ingestão e eficiência de ruminação são apresentados na tabela 3 . O consumo de MS expresso em $\mathrm{kg} \mathrm{dia}^{-1}$ apresentou comportamento linear decrescente, com estimativas dos valores máximo e mínimo de 0,968 e 0,765 $\mathrm{kg} \mathrm{dia}^{-1}$, para os níveis de FDN de 25 e 43\%, respectivamente, ao passo que o consumo de FDN, em kg dia- ${ }^{-1}$ cresceu linearmente com o aumento dos níveis de FDN.

Não foi observada influência das dietas $(\mathrm{P}>0,05)$ sobre a eficiência de ingestão, expressa em $\mathrm{g}$ $\mathrm{MS} / \mathrm{h}$. No entanto, houve decréscimo linear $(\mathrm{P}<0,05)$ da eficiência de ruminação, em g MS/h, com a elevação do nível de FDN da dieta. Segundo DULPHY et al. (1980), quando decrescem os constituintes da parede celular da dieta, aumentando o teor de amido, decresce o número de mastigações merícicas por bolo alimentar, o que pode ser observado com a redução linear verificada.

Ciência Rural, v.36, n.2, mar-abr, 2006. 
Tabela 3 - Valores médio para consumo de matéria seca (CMS), consumo de fibra em detergente neutro (CFDN), eficiência de ingestão (EI) e de ruminação (ERU), coeficientes de variação $(C V)$ e determinação $\left(R^{2}\right)$ e equações de regressão (ER), em função dos níveis de FDN das dietas experimentais.

\begin{tabular}{|c|c|c|c|c|c|c|c|}
\hline \multirow[b]{2}{*}{ Variáveis } & \multicolumn{4}{|c|}{ Nível de FDN } & \multirow[b]{2}{*}{$\mathrm{R}^{2}$} & \multirow[b]{2}{*}{ CV (\%) } & \multirow[b]{2}{*}{ ER } \\
\hline & 25 & 31 & 37 & 43 & & & \\
\hline CMS (kg/dia) & 0,968 & 0,959 & 0,773 & 0,765 & 0,72 & 6,85 & 1 \\
\hline CFDN (kg/dia) & 0,223 & 0,278 & 0,280 & 0,336 & 0,78 & 7,44 & 2 \\
\hline $\mathrm{EI}_{\mathrm{MS}}(\mathrm{g} \mathrm{MS} / \mathrm{h})$ & 274,48 & 282,04 & 219,54 & 262,65 & ---- & 21,51 & $Y=259,67$ \\
\hline $\mathrm{EI}_{\mathrm{FDN}}(\mathrm{gFDN} / \mathrm{h})$ & 63,37 & 81,34 & 79,47 & 115,22 & 0,53 & 20,45 & 3 \\
\hline $\mathrm{ERU}_{\mathrm{MS}}(\mathrm{g} \mathrm{MS} / \mathrm{h})$ & 133,12 & 123,34 & 91,25 & 93,94 & 0,49 & 16,41 & 4 \\
\hline $\mathrm{ERU}_{\mathrm{FDN}}(\mathrm{g} \mathrm{FDN} / \mathrm{h})$ & 30,69 & 35,71 & 33,03 & 41,25 & 0,29 & 15,60 & 5 \\
\hline
\end{tabular}

1.CMS $=1,25-0,012 \mathrm{FDN}^{* *}$

2. $\mathrm{CFDN}=0,119+0,005 \mathrm{FDN}^{* *}$

3. $\mathrm{EAL}_{\mathrm{FDN}}=11,14+2,23 \mathrm{FDN}^{* *}$

4. $\mathrm{ERU}_{\mathrm{MS}}=181,20-2,14 \mathrm{FDN}^{* *}$

$5 . \mathrm{ERU}_{\mathrm{FDN}}=21,32+0,42 \mathrm{FDN}^{* *}$

** significativo a $1 \%$ de probabilidade pelo teste $\mathrm{F}$

FDN = nível de fibra em detergente neutro da dieta

Os valores médios de eficiência de ingestão e ruminação da FDN apresentaram comportamento linear crescente, em função da elevação dos níveis de fibra das dietas. De acordo com DULPHY et al. (1980), a eficiência de ingestão e de ruminação da FDN aumenta quando o nível de fibra da dieta é aumentado. Tal fato foi confirmado por BÜRGER et al. (2000), que observaram aumento linear da eficiência de ruminação da FDN com o aumento da participação de volumoso nas dietas.

A distribuição da porcentagem de ingestão e ruminação, em oito períodos, nas 24 horas do dia, em função dos níveis de FDN das dietas experimentais, é apresentada nas figuras 1 e 2 .

Observa-se na figura 1, que em média 82,65\% da atividade de ingestão foi desempenhada nos períodos 1 , 3 e 4 . Isto pode ser explicado pelo manejo alimentar adotado, possibilitando uma concentração da atividade de ingestão em torno dos horários de distribuição da ração, que ocorreram às 8 e às 16 horas. Essa observação confirma o estímulo da distribuição de ração sobre a atividade de ingestão, conforme observado por FISCHER et al. (1998), e a concentração da atividade ingestiva durante o período diurno, como verificado por MIRANDA et al. (1999).

$\mathrm{Na}$ figura 2, verifica-se que a maior concentração da atividade de ruminação ocorreu no horário noturno, sendo que os períodos 6,7 e 8 corresponderam a 50,92\% do tempo de ruminação. Já a atividade de ruminação diurna ocorreu principalmente nos períodos 1 e 2 , ou seja, entre o primeiro e o segundo arraçoamento diário, e correspondeu a $24,20 \%$ da ruminação total. Os resultados obtidos são semelhantes aos encontrados pr FISCHER et al. (1998), que verificaram maior atividade de ruminação no período noturno, às primeiras horas do dia e entre $11 \mathrm{e}$ 15 horas.

\section{CONCLUSÕES}

O nível de FDN na dieta de cordeiros confinados não exerce influência sobre os tempos despendidos pelos animais em ingestão, ruminação e ócio, quando este é inferior a 44\%. A eficiência de ingestão e de ruminação da fração FDN aumenta com o incremento do nível de fibra na dieta. O estímulo ao consumo de alimento é desencadeado pelo ato de

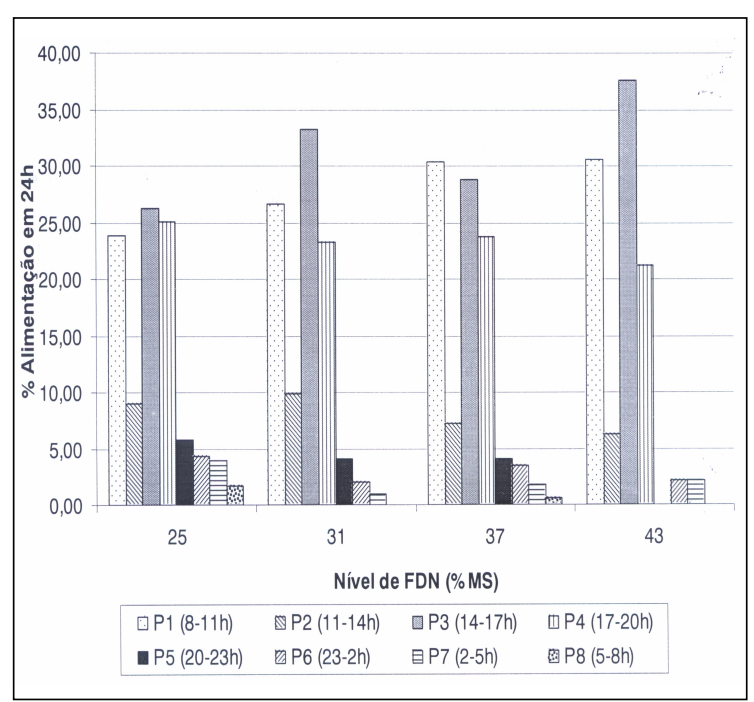

Figura 1 - Distribuição do tempo despendido em ingestão (\%), em oito períodos, nas 24 horas do dia, em função dos níveis de FDN das dietas experimentais.

Ciência Rural, v.36, n.2, mar-abr, 2006. 


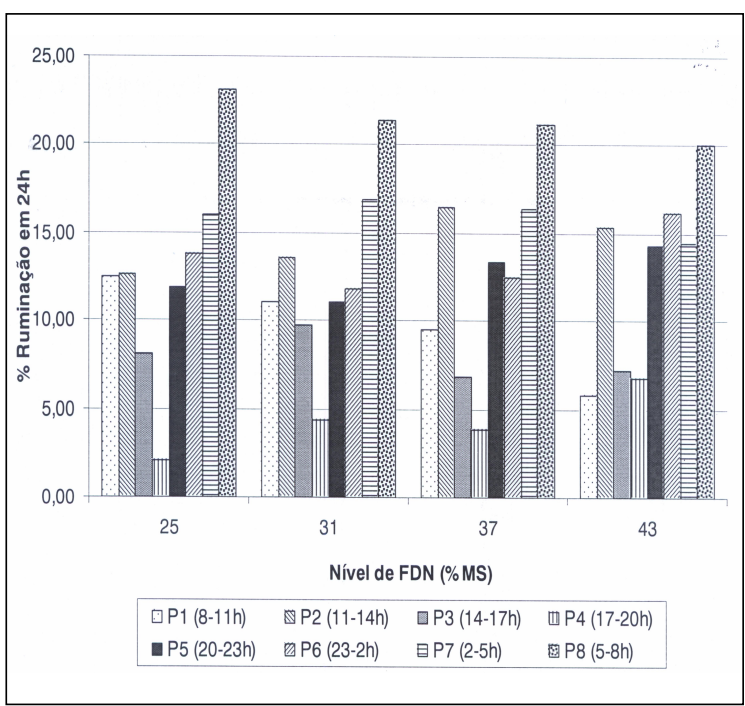

Figura 2 - Distribuição do tempo despendido em ruinação (\%), em oito períodos, nas 24 horas do dia, em função dos níveis de FDN das dietas experimentais.

fornecer o mesmo ao animal. Ovinos confinados possuem hábito de alimentação predominantemente diurno e de ruminação noturno.

\section{AGRADECIMENTOS E APRESENTAÇÃO}

Ao Conselho Nacional de Desenvolvimento Científico e Tecnológico/ Programa Institucional de Bolsas de Iniciação Científica (CNPq/ PIBIC). Pela concessão de bolsa aos pesquisadores Galvani e Pires.

Parte da Dissertação de Mestrado do primeiro autor apresentada à Universidade Federal de Santa Maria (UFSM), Santa Maria, RS, Brasil.

\section{REFERÊNCIAS}

ALBRIGHT, J.L. Feeding behavior of dairy catlle. Journal of Dairy Science, v.76, n.2, p.485-498, 1993.

BÜRGER, P.J. et al. Comportamento ingestivo em bezerros holandeses alimentados com dietas contendo diferentes níveis de concentrado. Revista Brasileira de Zootecnia, v.29, n.1, p.236-242, 2000.

CARVALHO, S. Desempenho e comportamento ingestivo de cabras em lactação alimentadas com dietas contendo diferentes níveis de fibra. 2002. 118f. Dissertação (Doutorado em Zootecnia) - Curso de Pós-graduação em Zootecnia Universidade Federal de Viçosa.

CHURCH, D.C. El rumiant: fisiología digestiva y nutrición. Zaragoza: Acribia, 1988. 641p.

DULPHY, J.P. et al. Ingestive behavior and related activities in ruminants. In: RUCKEBUSH, Y.; THIVEND, P. (Eds.). Digestive physiology and metabolism in ruminants. Lancaster: MTP, 1980. p.103-122.

FISCHER, V. et al. Padrões nictemerais do comportamento ingestivo de ovinos. Revista Brasileira de Zootecnia, v.27, n.2, p.362-369, 1998.
GONÇALVES, A.L. et al. Padrão nictemeral do pH ruminal e comportamento alimentar de cabras leiteiras alimentadas com dietas contendo diferentes relações volumoso:concentrado. Revista Brasileira de Zootecnia, v.30, n.6, p.1886-1892, 2001.

HODGSON, J. Grazing management: science into practice. Inglaterra: Longman Handbooks in Agriculture, 1990. 203p.

JOHNSON, T.R.; COMBS, D.K. Effects of prepartum diet, inert rumen bulk, and dietary polythylene glicol on dry matter intake of lactating dairy cows. Journal of Dairy Science, v.74, n.3, p.933-944, 1991.

MENDONCA, S.S. et al. Comportamento ingestivo de vacas leiteiras alimentadas com dietas à base de cana-de-açúcar ou silagem de milho. Revista Brasileira de Zootecnia, v.33, n.3, p.723-728, 2004

MERTENS, D.R. Predicting intake and digestibility using mathematical models of ruminal function. Journal of Animal Science, v.64, p.1548, 1987.

MERTENS, D.R. Using fiber and carbohydrate analyses to formulate dairy rations. Wisconsin: Us Dairy Forage Research Center, 1996. p.81-92. (Informational Conference with Dairy and Forages Industries).

MIRANDA, L.F. et al. Comportamento ingestivo de novilhas leiteiras alimantadas com dietas à base de cana-de-açúcar. Revista Brasileira de Zootecnia, v.28, n.3, p.614-620, 1999.

MORENO, J.A. Clima do Rio Grande do Sul. Porto Alegre: Secretaria da Agricultura, 1961. 41p.

OLIVEIRA, M.V.M. et al. rendimento de carcaça, mensurações e peso de cortes comerciais de cordeiros Santa Inês e Bergamácia alimentados com dejetos de suínos em confinamento. Revista Brasileira Zootecnia, v.31, n.3, p.1451-1458, 2002.

SAS - Statistical Analiys System. User'sGuide. Versão 6. 4.ed. North Caroline, 1997. 846p.

SILVA, D.J. Análise de alimentos: métodos químicos e biológicos. Viçosa, MG: Universidade Federal de Viçosa, 1990. 166p.

SNIFFEN, C.J. et al. A net carbohydrate and protein system for evaluating cattle diets. 2. Carbohydrate and protein availability. Journal of Animal Science, v.70, n.11, p.3562-3577, 1992.

TURINO, V.F. Substituição da fibra em detergente neutro (FDN) do bagaço da cana de açúcar in natura pela FDN da casca da soja, em dietas contendo alta proporção de concentrado para cordeiros confinados. 2003. $60 \mathrm{f}$. Dissertação (Mestrado em Agronomia) - Curso de Pós-graduação, Universidade de São Paulo.

VAN SOEST, P.J. Nutritional ecology of the ruminant. 2.ed. London: Constock, 1994. 476p.

WELCH, J.G.; HOOPER, A.P. Ingestion of feed and water. In: CHURCH, D.C. (Ed). The ruminant animal: digestive physiology and nutrition. Englewood Cliffs: Reston, 1988. p.108-116. 